Journal of Sustainable Agricultural Sciences
http://jsas.journals.ekb.eg/

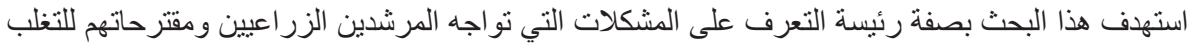

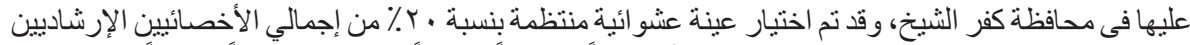

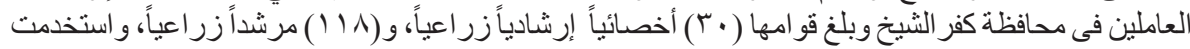

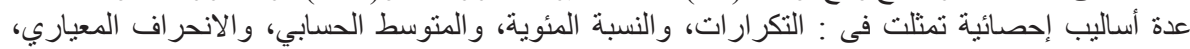

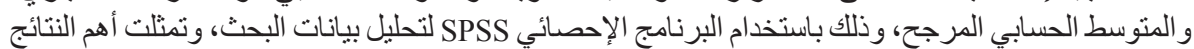

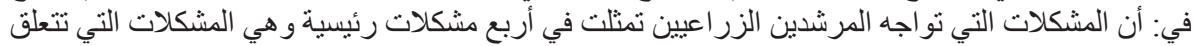

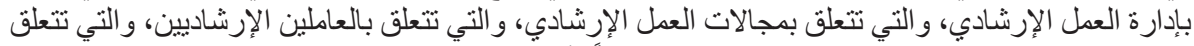

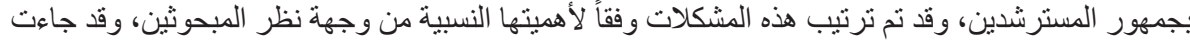

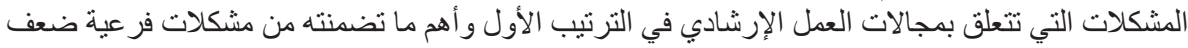

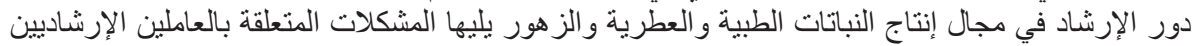

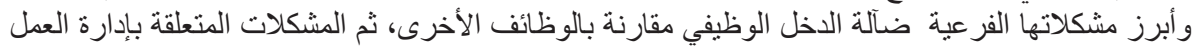

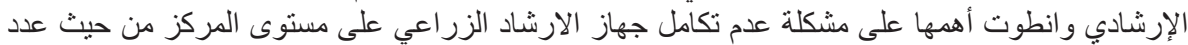

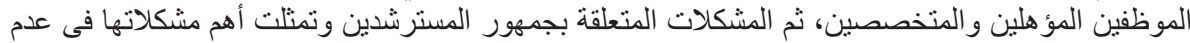

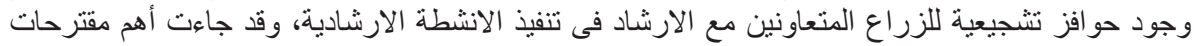

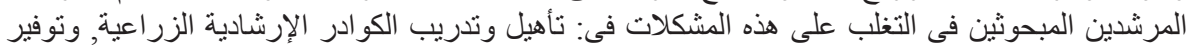

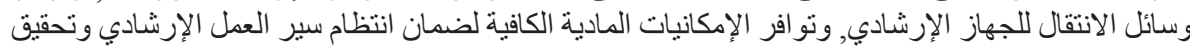

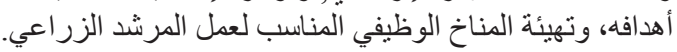

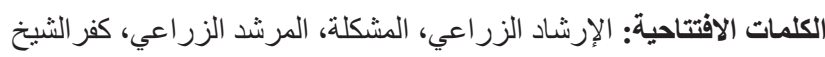

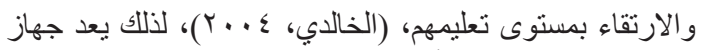

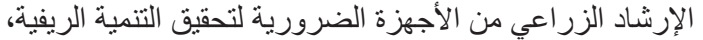

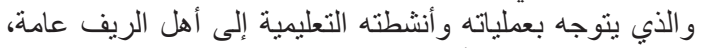

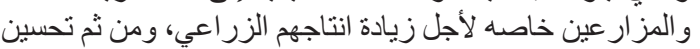

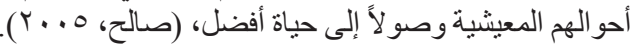

ويعمل الارشاد الزر اعى على تحقيق التنمية الزر اعية من خلال

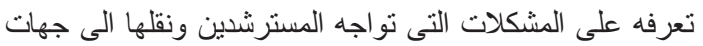

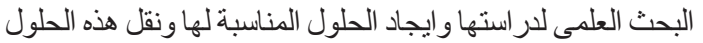

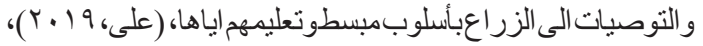

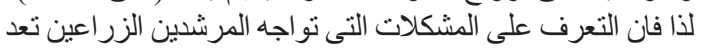
نقطة بداية لتوفير بيئة صلى لمالحة تنعكس ايجاباً على أدائهر.

ويمثل العاملون بالجهاز الإرشادي حجر الزاوية في تحقيق

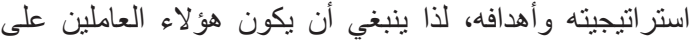

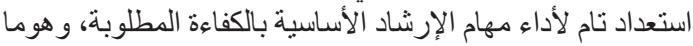

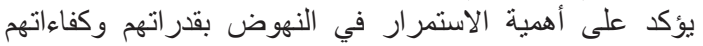

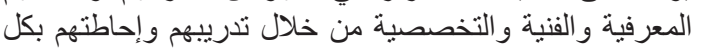

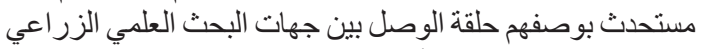

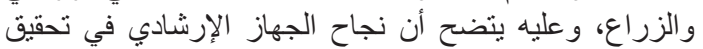

المقدمة والمشكلة البحثية

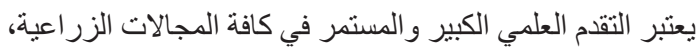

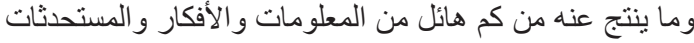

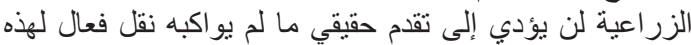

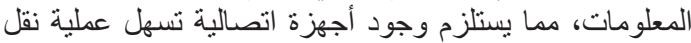

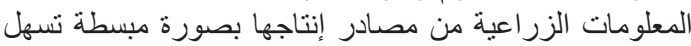

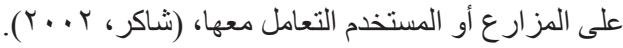

كما أصبح من الضروري على الهيئات و المنظمات الزر اعية

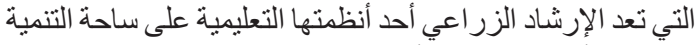

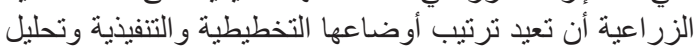

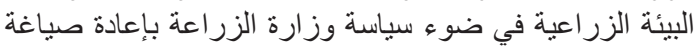

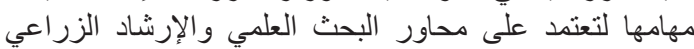

و اقتصاديات الإنتاج، (و هبه، وسعد الدين، ل199 (1).

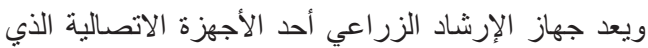

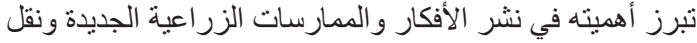

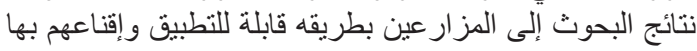

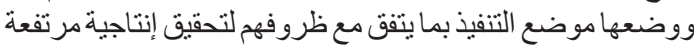


إداريةو تتظيمية، ومشكلات خاصة بعلاقات العمل، ومشكلات خاصة

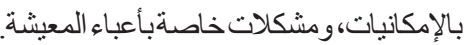

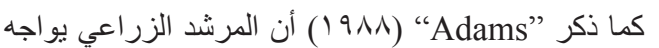

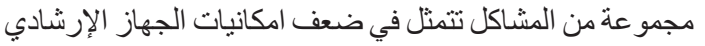

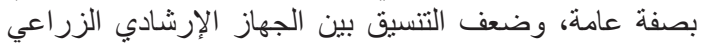

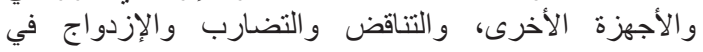

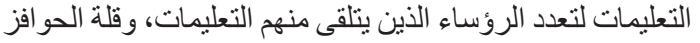

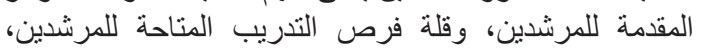

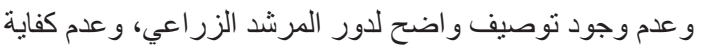

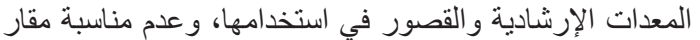
عمل المرشد الزر اعي على مستوى القرية.

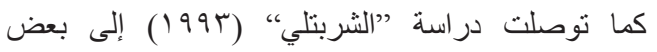

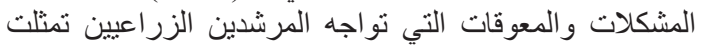

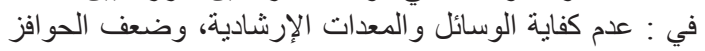

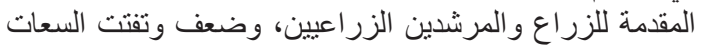

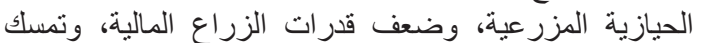
الزراع بالعادات و التقاليد و المفاهيم القديمة.

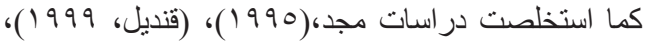

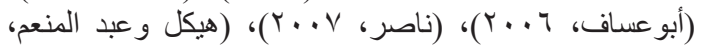

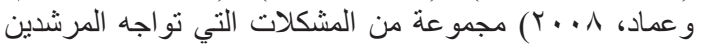

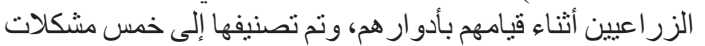
رئيسية تضم كلاً منها عدد من المشكلات الفر الفر عية كما يلي:

أو لاً: مشكلات إدارية وتنظيمية:

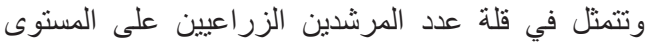

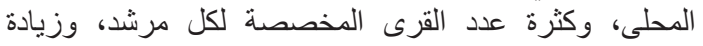

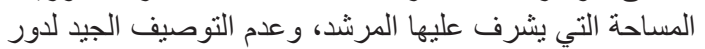

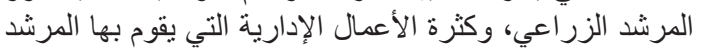

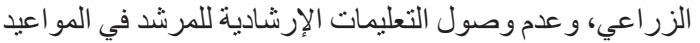

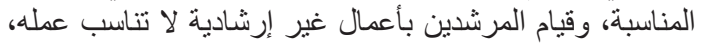

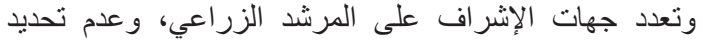

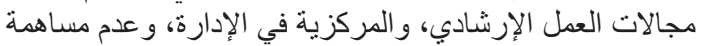

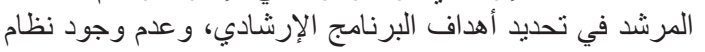

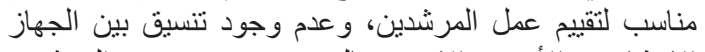

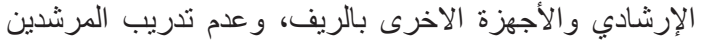

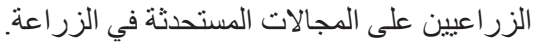

ثنانياً: مشكلات خاصة بعلاقات العمل:

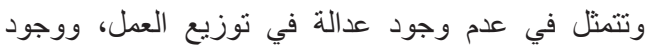

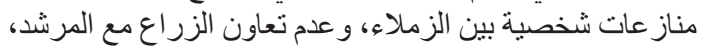

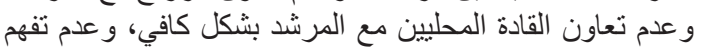

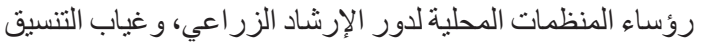

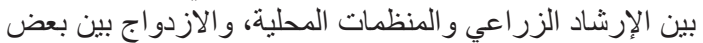

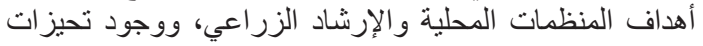

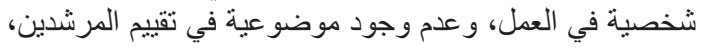
قلة فرص الاتصال و التحدث مع ودي الرئيس المباثر.

ثالثاً: مشكلات خاصة بالإمكانيات اللازمة للعمل الإرشادي:

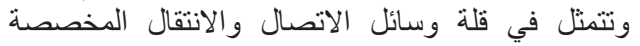

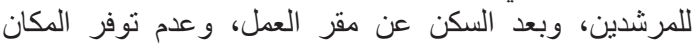

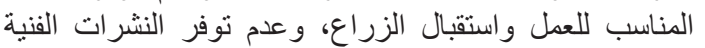

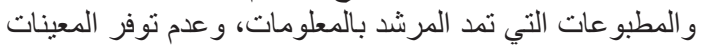

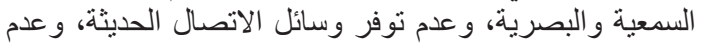

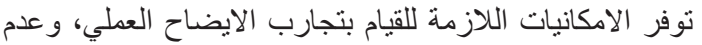

أهدافه ورسالته يتوقف بالدرجة الأولى على كفاءة ومهارة ومقدرة

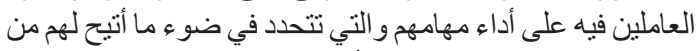

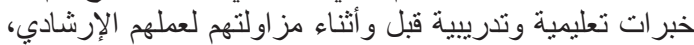

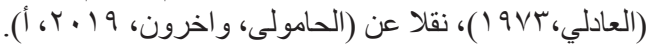

و هنالك العديد من المتغيرات المؤثرة على العمل الارشادى العادي

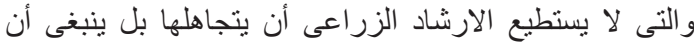

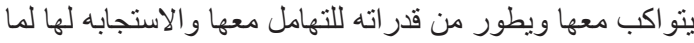

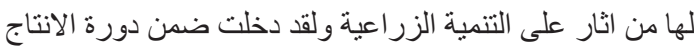

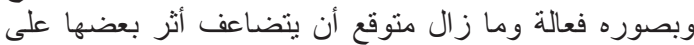

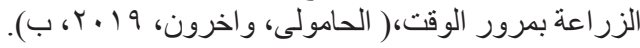

ويتوقف نجاح وفعالية العمل الارشادي في القيام بمسئولياته

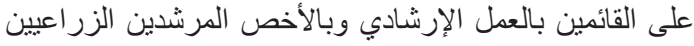

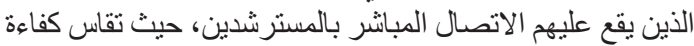

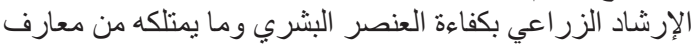

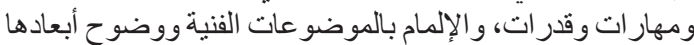

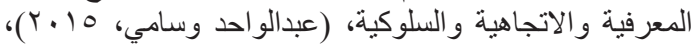

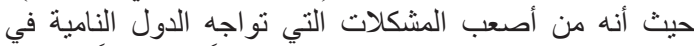

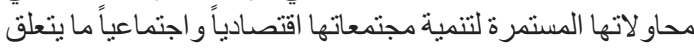

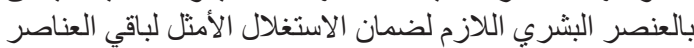

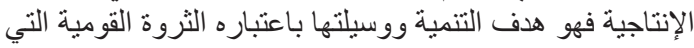

يعقد عليها الآمال و الرخاء في المجتمع، (عبدالحليه، ؟ . . ب). ويعتبر المرشد الزراعي هو المسئول عن تقديم الخدمة

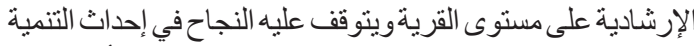

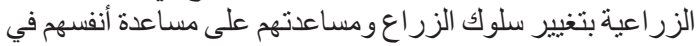

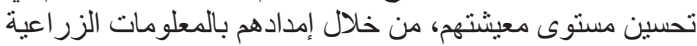

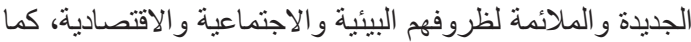

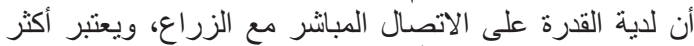

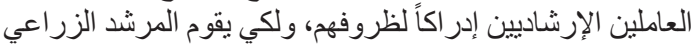

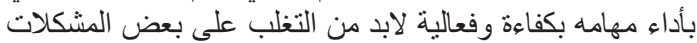

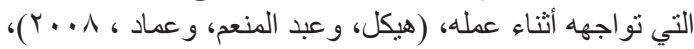

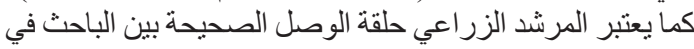

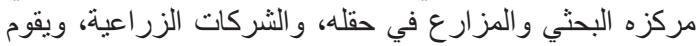

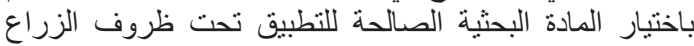

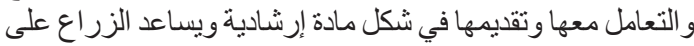

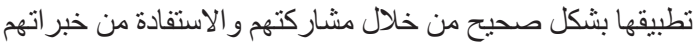

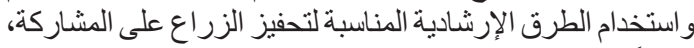

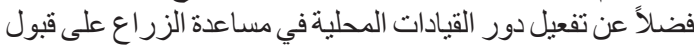

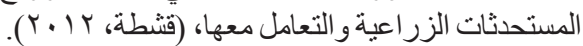

ولاشك أن نجاح المرشد الزراعي في أداء مهامه الوظيفية

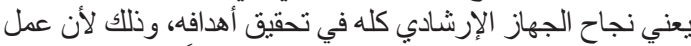

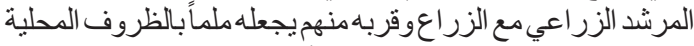

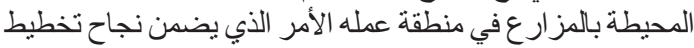

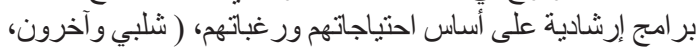

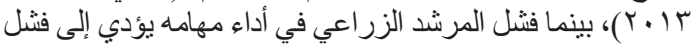

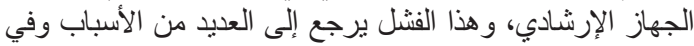

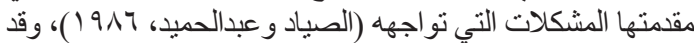

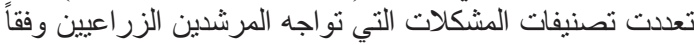

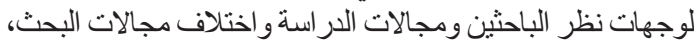

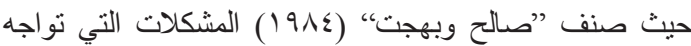

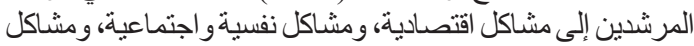

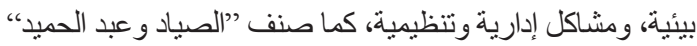
(1919 1 ) المشكلات التي تواجه المرشدين الزر اعيين إلى مشكلات

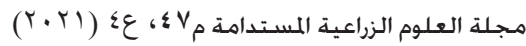




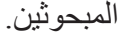

r- التعرف على مستوى وجود المشكلات التي تو اجه المرشدين

الزر اعيين المبحوثين وتحديد اهميتها النسبية.

rــ التعرف على أهم مقترحات المرشدين الزر اعيين المبحوثين

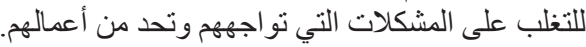

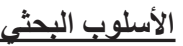

أو لاً: التعاريف الإجر ائية للمتغير ات وكيفية قياسها:

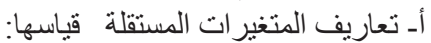

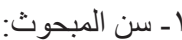

ويقصد به عدد السنوات التي عاشها المبحوث منذ ميلاده وحتى وقت تجمع بيانات البحث مقربة إلى "أقرب سنة ميلادية،

وتم قياسه باستخدام الأرقام الخام المعبرة عن عدد السنوات التئ.

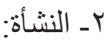

ويقصد بها المكان الذي وُلد ونشأ فيه المرشد الزراعي

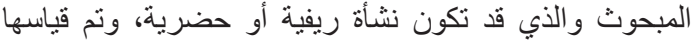

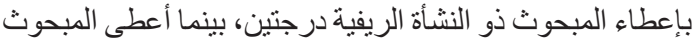
ذو النشأة الحضرية درجة واحدة.

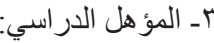

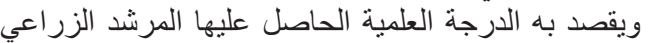

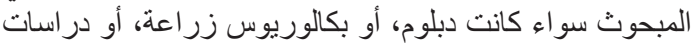

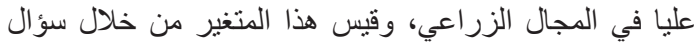

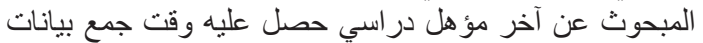

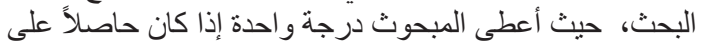

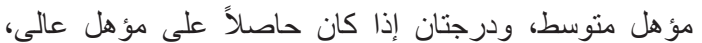

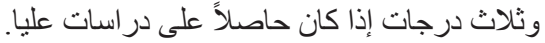

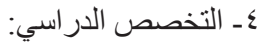

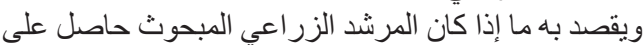

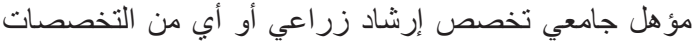

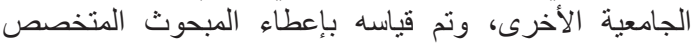

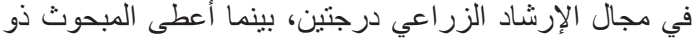

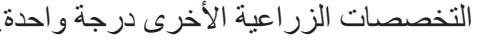

هـ الخبرة الوظيفية الارشادية:

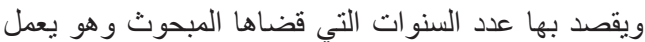

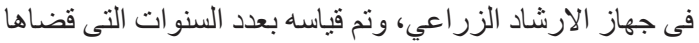

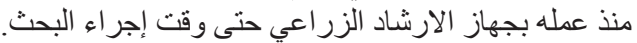

7ـ المسافة بين محل الإقامة ومكان العمل:

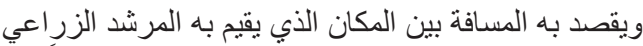

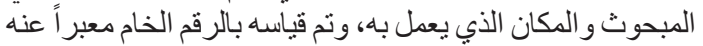

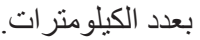

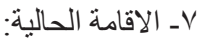

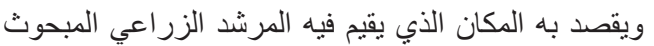

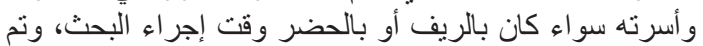

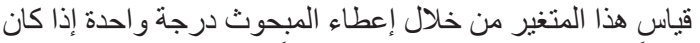
مقيماً بالحضر ، ودرجنان إذا كان مقيماً بالريف.

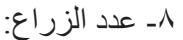

ويقصد به عدد الزراع الذين يقدم لهم المبحوث النصائح

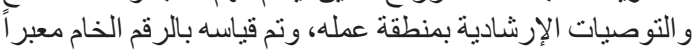

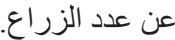

9ـ المساحة الزر اعية الإشر افية:

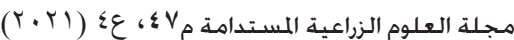

توفر المكتبات والمر اجع اللازمة لتزويد المرشد بالمعلومات.

رابعاً: المشكلات النفسية والاجتماعية:

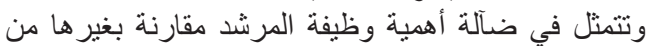

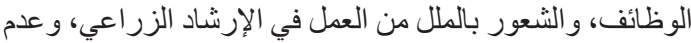

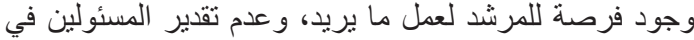

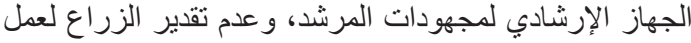

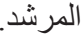

خامساً: مشكلات خاصة بدخل المرشد الزر اعي:

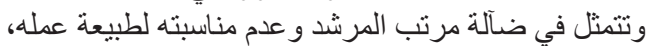

وقلة الأجور الإضافية، وعدم وجود بدل طبية وليعة عمل، وضآلة الاخل بالمقارنة بالوظائف الاخرى.

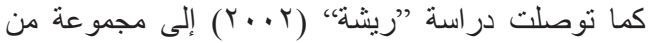

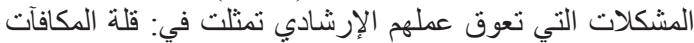

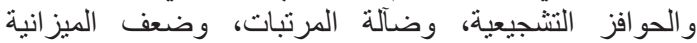

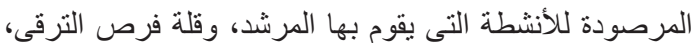
وقلة عدد المرشدين الموجودين بالمئن بـاطق الجديدة.

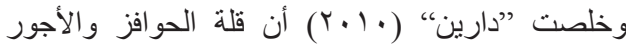

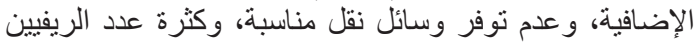

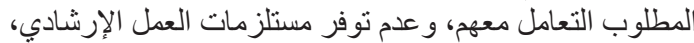

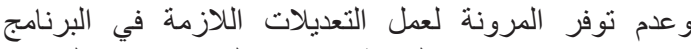

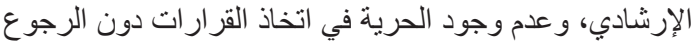
للرؤساء أهم المشكلات التي تقابل المرشدين.

كما برزت في الأونة الاخيرة العديد من المشكلات التى تواجه

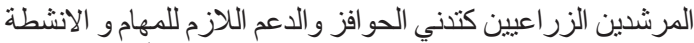

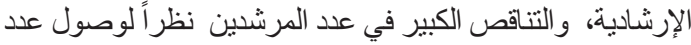

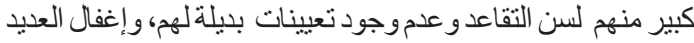

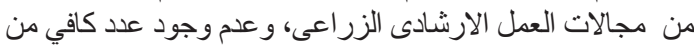

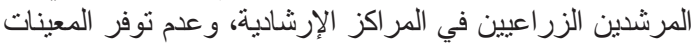

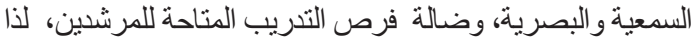

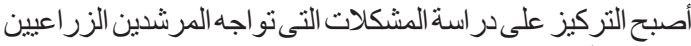

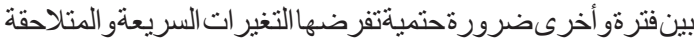

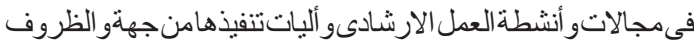
المجتمعية خاصة فى ظل جائحة كورونا (كوفيد 9 (1) من جهة الخدئ أخرى

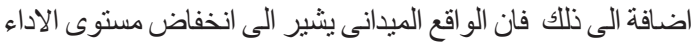

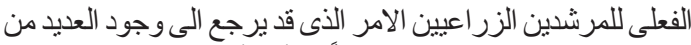

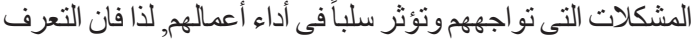

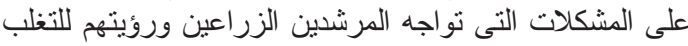

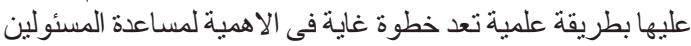

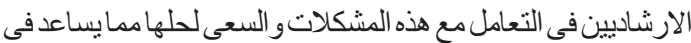

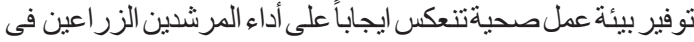

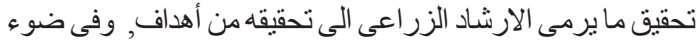

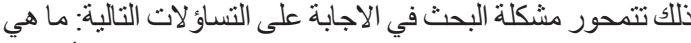

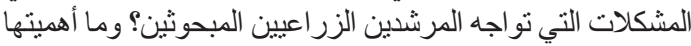

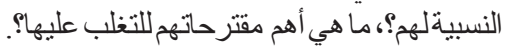

أهداف البحث

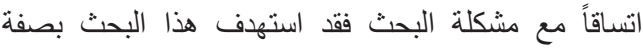

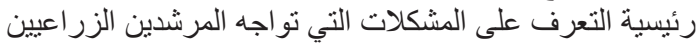

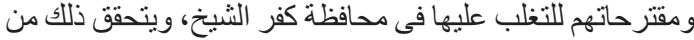
خلال التعرف على الأهداف الفرعية التالية: 1 ـ التعرف على بعض الخصائص المميزة للمرشدين الزر اعيين 
في ثماني وثمانون مشكلة موز عه على أربع مشكلات رئيسة و هي:

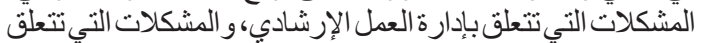

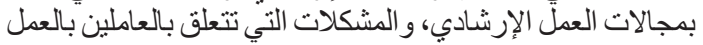

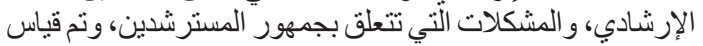

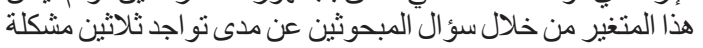

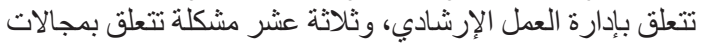

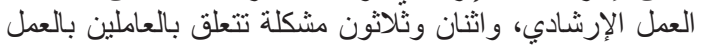

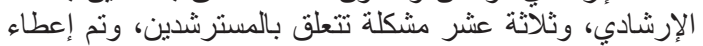

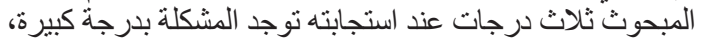

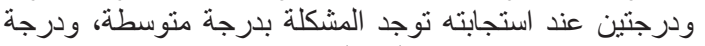

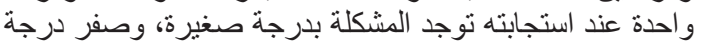

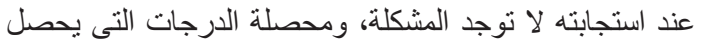

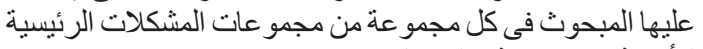
الأربعة تحدد درجة تول اجذها.

ثنانباً: منطقة وشاملة و عينة البحث:

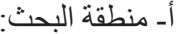

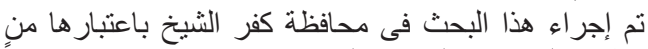

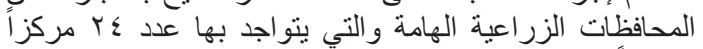

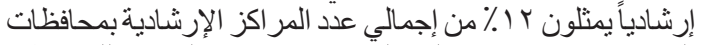

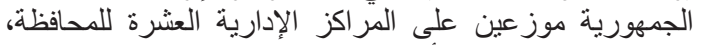

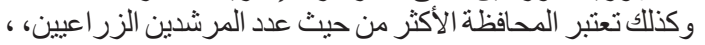

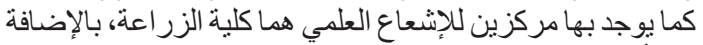

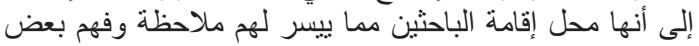
جو انب الظاهرة موضع البحث، وكذللك سهولة جمع البيانات.

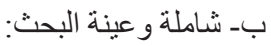

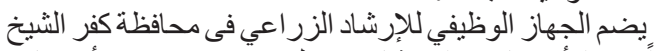

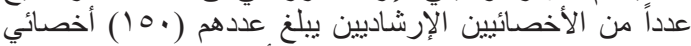

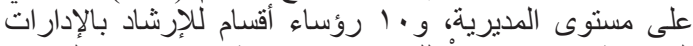

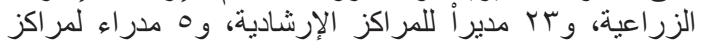

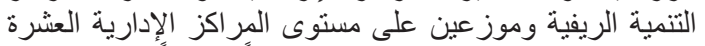

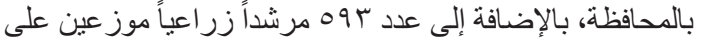

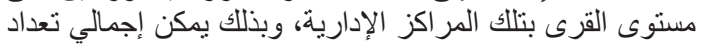

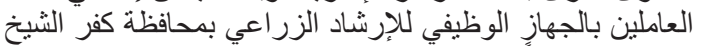

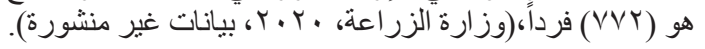

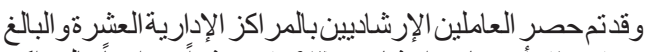

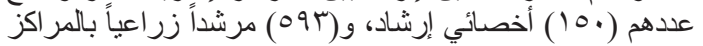

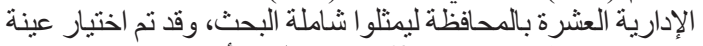

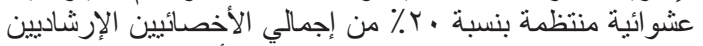

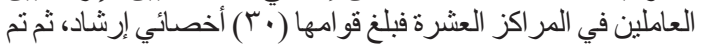

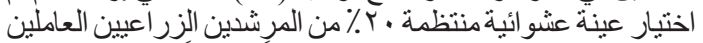

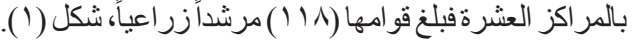

ثالثاً: أسلوب جمع وتحليل البيانات:

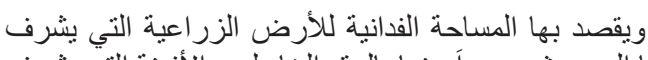

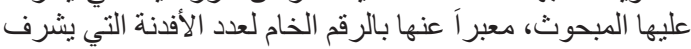
عليها في نطاق عمله.

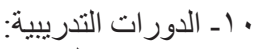

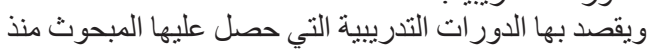

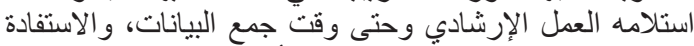

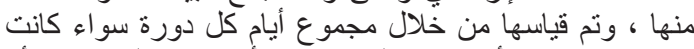

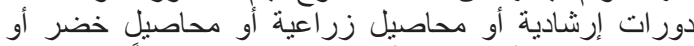

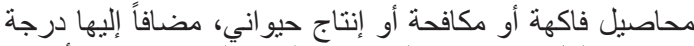

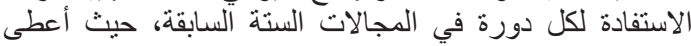

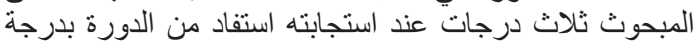

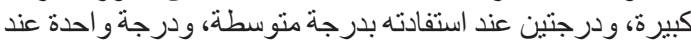

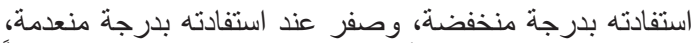

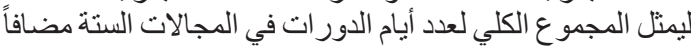

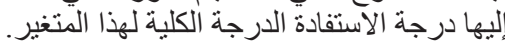

11 ـ المصادر المرجعية المعرفية:

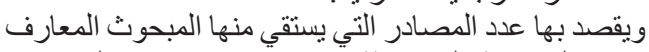

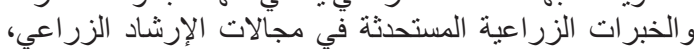

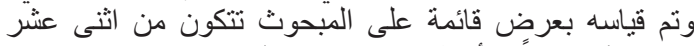

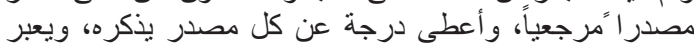
مجموع الدرجات التي يحصل عليها درجة المبحوث عن هذا المتغير.

r ا ـالمهام الوظبفية للمرشدين الزر اعيين:

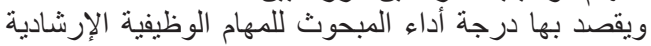

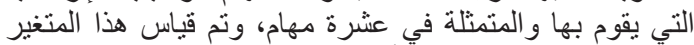

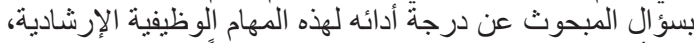

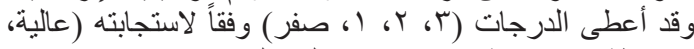

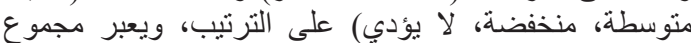

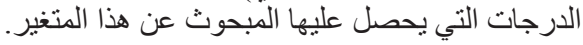

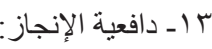

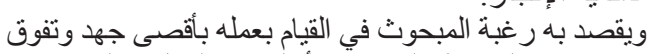

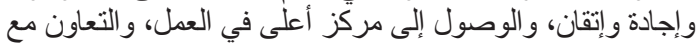

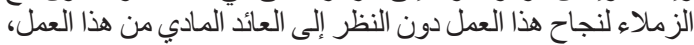

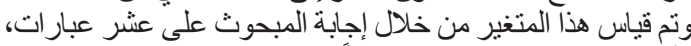

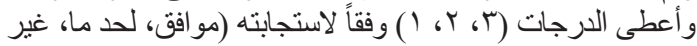

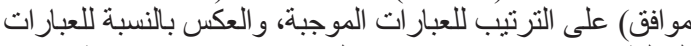

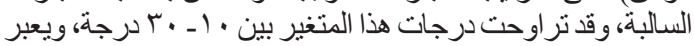

مجمو ع الدرجات التي يحصل عليها المبحوث هن عن هذا المتغير. ب- المتغير التابع وطريقة قياسه:

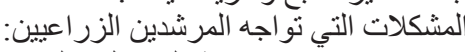

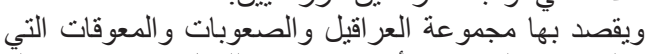
تو اجه المرشدين الزر اعيين أثناء ممارستهم للعمل الإرشادي متمثلة

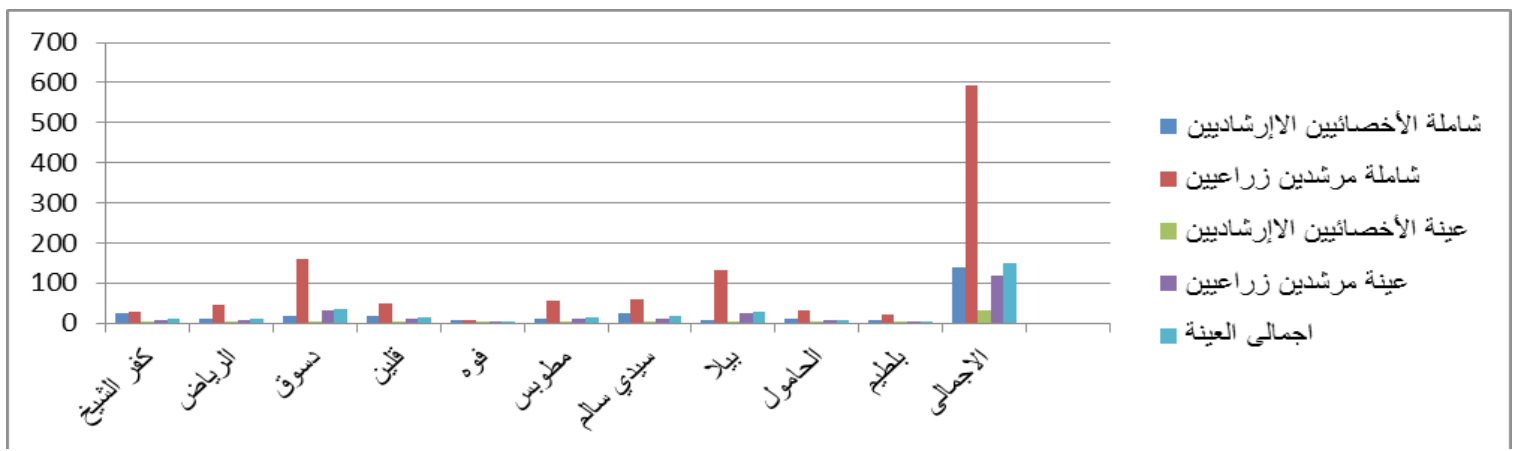

شكل (1) توزيع شاملة وعينة الدراسة على المراكز الإدارية العشرة بمحافظة كفر الثيخ.

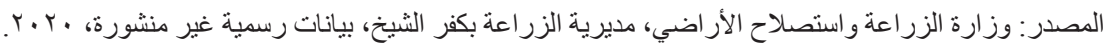

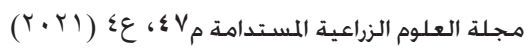




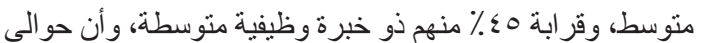

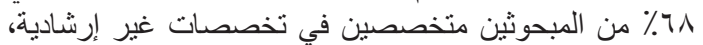

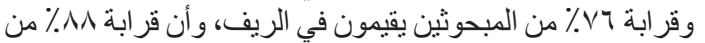

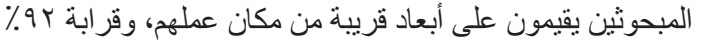

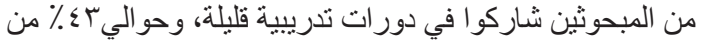

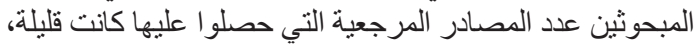

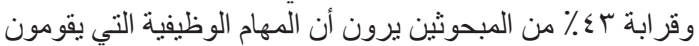

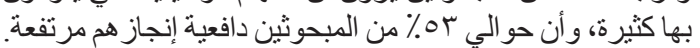
ثانباً: المشكلات التي تو اجه المرشديين الزر اعبين

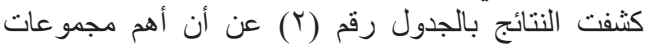

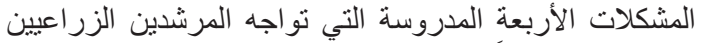

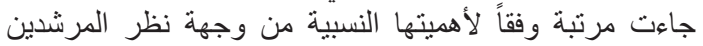

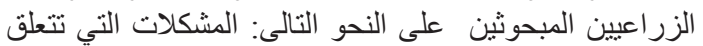

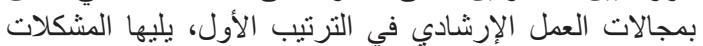

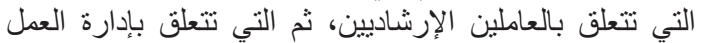

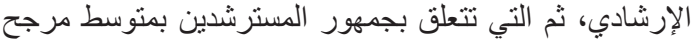

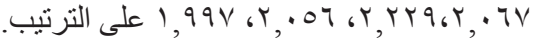
ثالثا: الأهمية النسبية للمشكلات الفرعية لكل مجموعة من
تم استيفاء البيانات الميدانية لتحقيق أهداف البحث باستخدام

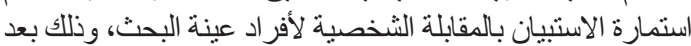

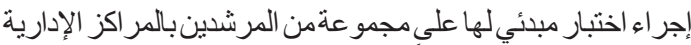

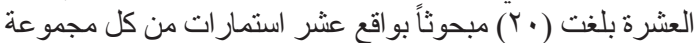

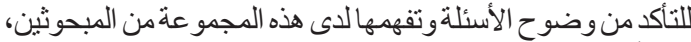

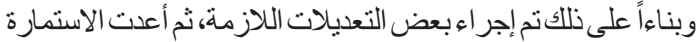

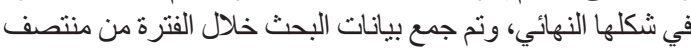

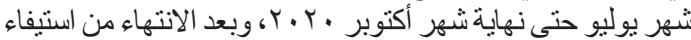

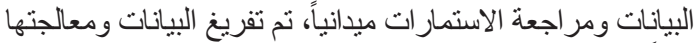

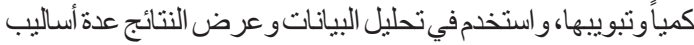

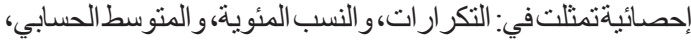

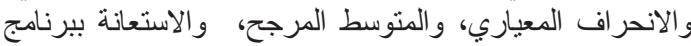
SSPS

النتائج ومناقشتها

أولاً: بعض الخصائص المميزة للمرشدين الزر اعيين المبحوثين

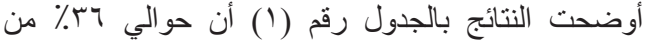

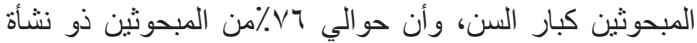
ريفية، وأن حوالي 00٪ من المبحوثين حاصلين على مؤهل

\begin{tabular}{|c|c|c|c|c|c|}
\hline \multicolumn{6}{|c|}{ جدول (1) توزيع المرشدين الزراعيين المبحوثين وفقاً لبعض الخصائص المميزة لهه. } \\
\hline$\%$ & العدد & 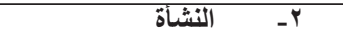 & $\%$ & العدد & السن \\
\hline$v \uparrow, \varepsilon$ & $11 \pi$ & ذو نشأة ريفية & $M \Psi, \varepsilon$ & $0 \leqslant$ & صغير (q r - • ؟) سنة \\
\hline rT & ro & ذه نشأة حضر بة & $r V, r$ & $\varepsilon \cdot$ & متوسط (اء - • (0) سنة \\
\hline , & & لو سمه حصري & $r q, \varepsilon$ & $0 \leqslant$ & كبير (10 _. • سنة \\
\hline$\%$ & العدد & 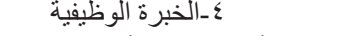 & $\%$ & العدد & 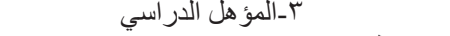 \\
\hline$r \leqslant, 0$ & 01 & منخفضة (Y-Y (1) سنة & $00, \varepsilon$ & Ar & متوسط \\
\hline$\leq \leqslant, 7$ & 77 & متوسطة (7 (19-1) سنة & $\leqslant 1,9$ & זיד & 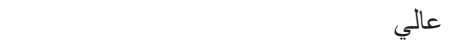 \\
\hline$r \cdot, 9$ & m & 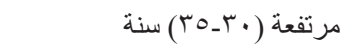 & $r, v$ & $\varepsilon$ & در اسات عليا \\
\hline$\%$ & 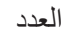 & 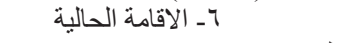 & $\%$ & 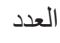 & مـالتخصص الدراسي \\
\hline Vo,, $\mathrm{V}$ & 114 & الريف & $\top \wedge, r$ & 1.1 & تخصصات آخرى " \\
\hline$r \varepsilon, r$ & r & 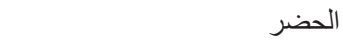 & $r^{\top}, \wedge$ & $\varepsilon v$ & إرشاد زراعي \\
\hline$\%$ & 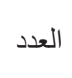 & يـ عدد الدورات التدريبية & $\%$ & 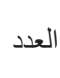 & Vـ المسافة بين محل الإقامة ومكان العمل \\
\hline 91,9 & 147 & قليلة (•-rr) دورة & $\wedge \vee, \wedge$ & $1 \pi$. & صغيرة (1-Tس) كيلو متر \\
\hline $0, \varepsilon$ & $\wedge$ & متوسطة (ع ז_r דו) دورة & 11,0 & IV & متوسطة (ع ب_r7) كيلو متر \\
\hline$r, v$ & $\varepsilon$ & 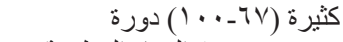 & $\cdot, \mathrm{V}$ & 1 & 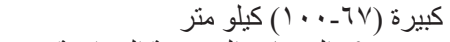 \\
\hline$\%$ & 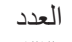 & 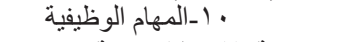 & $\%$ & 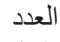 & جـ المصادر المرجعية الزراعية \\
\hline$r, r$ & r & منخفضة (V - V 17) مهمة & $\varepsilon r, r$ & $7 \varepsilon$ & منخفضة (r-T) مصدر \\
\hline ro, 1 & or & متوسطة (V - Y - Y (Y) مهمة & $r v, \wedge$ & 07 & متوسطة (V- I' (1) مصدر \\
\hline$\leqslant r, T$ & זי & 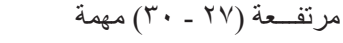 & 11,9 & rA & مرتفعة (r I (1) مصدر \\
\hline & & & $\%$ & 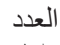 & | (ا-_دافعية الإنجاز \\
\hline & & & Ir, & 11 & منخفضة (Y- Y P (Y) درجة \\
\hline & & & $r \leqslant, 0$ & 01 & 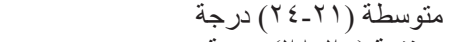 \\
\hline & & & or, $\varepsilon$ & 19 & مرتفعة (Y (Y) درجة \\
\hline
\end{tabular}

جدول (ץ) الأهمية النسبية للمشكلات التي تواجه المرشدين الزراعيين المبحوثين.

\begin{tabular}{|c|c|c|c|}
\hline الترتيب & المتوسط المرجح & عدد المشكلات الفرعية داخل كل مجموعة & مجال المشكلة \\
\hline 1 & r, rYq & ir & المشكلات التي تتعلق بمجالات العمل الإرشادي \\
\hline r & $r, \cdot T V$ & Tr & المشكلات التي تتعلق بالعاملين الإرشاديين \\
\hline$r$ & $r, .07$ & $r$. & المشكلات التي تتعلق بإدارة العمل الإرشادي \\
\hline$\varepsilon$ & $1,99 \mathrm{~V}$ & $1 \pi$ & المشكلات التي تتعلق بجمهور المسترشدين \\
\hline
\end{tabular}

الكصدر: حسبت من استمارة الاستبيان.

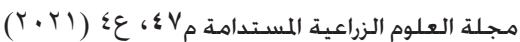


مشكلة ضعف العلافة بين الإرشاد الزر اعي و أجهزة البحث العلمي

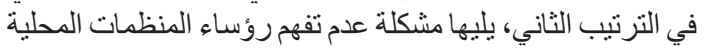

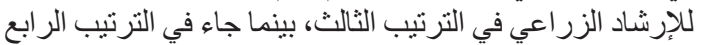

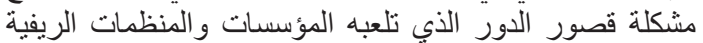

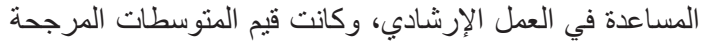
لهذه المشكلات
المجمو عات الرئيسة المدروسة:

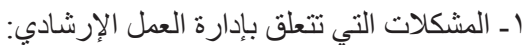

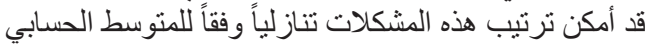

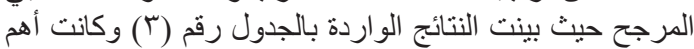

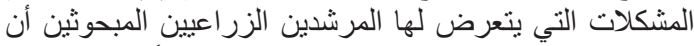

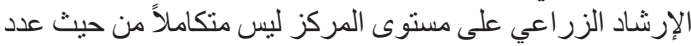

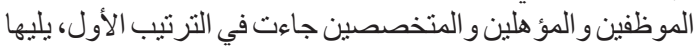

جدول (ّ) توزيع المرشدين الزراعيين المبحوثين وفقاً لارجة تواجد المشكلات المتعلقة بإدارة العمل الإرشادي.

\begin{tabular}{|c|c|c|c|c|c|c|c|c|c|c|c|}
\hline \multirow{3}{*}{ الترتيب } & \multirow{3}{*}{ 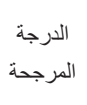 } & \multirow{2}{*}{\multicolumn{2}{|c|}{ لا توجد }} & \multicolumn{6}{|c|}{ درجة التواجد } & \multirow{3}{*}{ المشكلات } & \multirow{3}{*}{ 5 } \\
\hline & & & & \multicolumn{2}{|c|}{ صغيرة } & \multicolumn{2}{|c|}{ متوسطة } & \multicolumn{2}{|c|}{ كبيرة } & & \\
\hline & & $\%$ & العدد & $\%$ & العدد & $\%$ & العدد & $\%$ & العدد & & \\
\hline$\varepsilon$ & $r, r v$ & $r, r$ & $\varepsilon$ & ${ }^{\prime}, r$ & 11 & $r \cdot, \varepsilon$ & $\leq 0$ & $0 \leqslant, V$ & 1) & 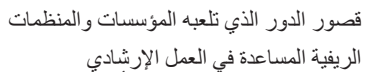 & 1 \\
\hline Ir & $r, 11$ & $\varepsilon, 1$ & 1 & 19,7 & rq & $r v, r$ & 00 & $r q, r$ & 01 & 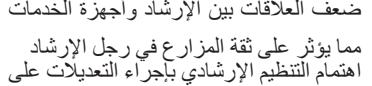 & r \\
\hline 9 & r, ro & $r, \varepsilon$ & 。 & $\wedge, \wedge$ & $1 T$ & $\varepsilon v, r$ & v. & $\varepsilon \cdot, 0$ & 7. & المستوى القومي وإغفاله على المستوى الإقليمي & $r$ \\
\hline ri & 1,99 & $\wedge, 1$ & ir & $r \leqslant, r$ & rq & $r \wedge, \varepsilon$ & $\varepsilon r$ & $r q, r$ & 01 & السلطاجة إلّى تحديد الأدو ار و المستويات وبالتالي & $\varepsilon$ \\
\hline 10 & $r, \cdot q$ & \urcorner,$\wedge$ & 1. & $17, r$ & $r \varepsilon$ & $r v, \wedge$ & 07 & $r q, r$ & 01 & 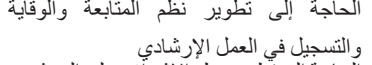 & 。 \\
\hline 11 & $r, 10$ & $\wedge, 1$ & ir & $1 r, r$ & 11 & $r 4,0$ & $0 \leqslant$ & $\varepsilon r, r$ & $T \varepsilon$ & الزر اعبين المحلى نطوير نطم الإتراق على المر تشدين & 1 \\
\hline rı & $1,7 \leqslant$ & $r \cdot, q$ & r & $11, r$ & tr & $r v, r$ & 00 & $r r, T$ & ro & عدم وصول الهيكل التنظيمي إلى مستوى القرية & $\mathrm{v}$ \\
\hline iv & $r_{,} \cdot 7$ & $7, \wedge$ & 1. & 10,0 & rt & $\leqslant r, 7$ & Tr & $r_{0}, 1$ & or & للظروف إلمحلية المسرين حريه السصرق وقها & $\wedge$ \\
\hline 1. & $r, r$ & $1 \cdot, 1$ & 17 & $\varepsilon, \vee$ & $\mathrm{v}$ & $r q, r$ & 01 & $\varepsilon 0, r$ & TV & الجهاز الإرشادي في وسائل الاتصال بين مستويات & 9 \\
\hline 1 & $r, 09$ & $1, \varepsilon$ & r & $\varepsilon, \gamma$ & $\checkmark$ & $r v, Y$ & 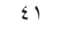 & $77, r$ & $9 \wedge$ & هنكاملاً من حيث عدد الموظفين والمؤهلين & 1. \\
\hline 7 & r, ro & $\wedge, 1$ & ir & $\wedge, 1$ & ir & $r+$, & ro & $7 \cdot, 1$ & 19 & 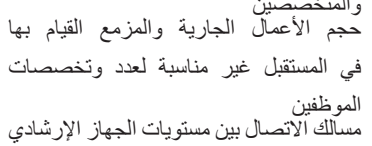 & 11 \\
\hline ir & $r, 1$. & $\wedge, \wedge$ & ir & $1 \leqslant, r$ & r) & $r_{0}, 1$ & or & $\leqslant 1,9$ & Tr & ليست بالسرعة المرجوة بينها وبين جمهور & IT \\
\hline$r \cdot$ & $r_{,} \cdot$ & $1 \cdot, \wedge$ & 17 & $1 \leqslant, 9$ & rr & $r v, r$ & 00 & $r v, r$ & 00 & أسلإوباد توجيه الرؤساء للمرشدين غير مناسب & 14 \\
\hline ry & $1, \mathrm{VA}$ & $r r$, & $r \varepsilon$ & $1 \cdot, 1$ & 10 & $r+$, & $\leq 9$ & $r, \wedge$ & 0. & الإرشادي وجود برنامج محدد ومرسوم للعقل & $1 \leqslant$ \\
\hline $1 \varepsilon$ & $r, \cdot 9$ & $1 \cdot, 1$ & 10 & 19,7 & rq & $r \cdot, q$ & ri & $\varepsilon q, r$ & vr & كثرة الأعمال الإدارية و المكتبية & 10 \\
\hline 19 & $r, \cdot r$ & $1 \leqslant, r$ & r) & $1 \leqslant 9$ & r & ro, & rV & $\leq 0,9$ & 71 & ازدواج الإشر اف الإداري و الفني & 17 \\
\hline rt & 1,90 & $1 \leqslant, 9$ & rt & 15,0 & r. & $r$ r, & 0 . & $r v, \Lambda$ & 07 & المسافات الكبيرة بين القرب المخصصة للمرشد & IV \\
\hline$r \cdot$ & 1,49 & ro, 1 & or & 10,0 & rt & ro, & re & $r \leq, r$ & ד & كثرة الاجتماعات مع الرؤسّاء & 11 \\
\hline rq & $1,7 \leqslant$ & $r r$, & $r \varepsilon$ & $11, r$ & rV & $r, 1$ & $\leqslant 7$ & $r v, r$ & 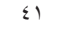 & تعدد جهات الإشرافَ على المرشد الزراعي & 19 \\
\hline 11 & $r, \cdot 0$ & $v, \varepsilon$ & 11 & 11,9 & ru & $r_{0}, 1$ & or & $r \wedge, 0$ & ov & ضإرشادي التنسيق بين المستويات المختلفة للجهاز & 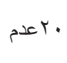 \\
\hline$\wedge$ & $r, r^{\prime}$ & 7,1 & 9 & 11,9 & ra & $1 \mathrm{~V}, 7$ & זד & $o v, \varepsilon$ & 10 & بطء اتخاذ القرار ات الإدارية و المالية ل & r) \\
\hline 17 & $r, \cdot r$ & 11,0 & iv & 9,0 & $1 \leq$ & $r q, r$ & 01 & $r q, \wedge$ & 09 & الإرشادية وجود حطيط منط لمعطم الاعمل & rt \\
\hline$r \varepsilon$ & $1, \wedge \varepsilon$ & $r, 7$ & rr & $\wedge, 1$ & ir & ro, 1 & or & ro, & or & تعدد وتضارب التعليمات الواردة إلى المرشد & זr \\
\hline ro & l, גז & 11,9 & rی & $11, r$ & rV & $r r, 7$ & ro & $r q, r$ & 01 & الجهاز الإرشادي المرشدين بالتغيرات النتظيميه في & $r \varepsilon$ \\
\hline rT & $1, \wedge \wedge$ & $11, r$ & TV & $1 \cdot, 1$ & 10 & $r v, r$ & 00 & $r \leqslant, 0$ & 01 & للوظيفة وجود مسئولية محددة وسلطة واضحة & ro \\
\hline rv & 1,174 & $r r, \cdot$ & $r \varepsilon$ & $1 \leqslant, r$ & r) & $r v, \cdot$ & $\varepsilon$. & $r_{0}, \wedge$ & or & تلدخل الأجهزة التنفيذية على المستوى المحلي & r \\
\hline$r$ & $r, \varepsilon V$ & $0,\{$ & $\wedge$ & $\varepsilon, 1$ & 7 & $r q, 1$ & $\varepsilon r$ & 71,0 & 91 & : & $r V$ \\
\hline r & $r, r \wedge$ & $0, \varepsilon$ & $\wedge$ & $0, \varepsilon$ & $\wedge$ & $r_{0}, 1$ & or & $0 \leqslant, 1$ & A. & عدم تَفهم رؤساء المنظمات المحلية لدور & rA \\
\hline . & r & 7,1 & 9 & 7,1 & 1. & $r^{\top}, \wedge$ & $\leq v$ & $00, \varepsilon$ & Ar & والباحثن الإرشاديين والتنسيق بين الاكاديميين & rq \\
\hline $\mathrm{v}$ & $r, r \varepsilon$ & 7,1 & 9 & $1 \cdot, \wedge$ & 17 & $r, \varepsilon$ & $r q$ & 07,1 & $\Lambda \varepsilon$ & الإرشاد الزود نتسيق وتعاون بين الجامعات وجهاز & $r$. \\
\hline
\end{tabular}




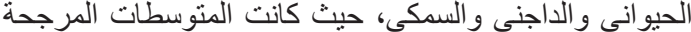

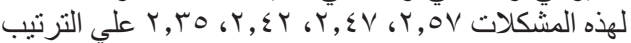

بـ المشكلات المتعلقة بالعاملين الإرشادبين:

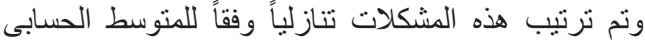

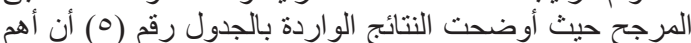

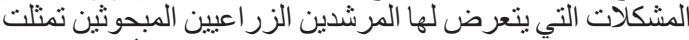

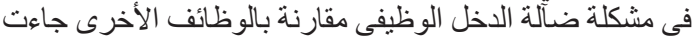

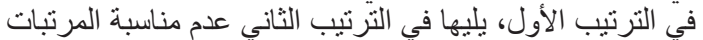

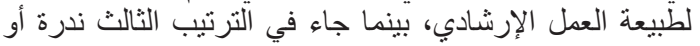

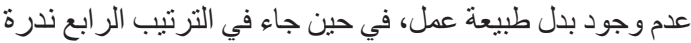

r ـ المشكلات التى تتعلق بمجالات العمل الإرشادي:

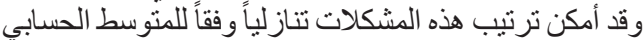

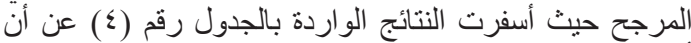

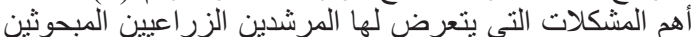

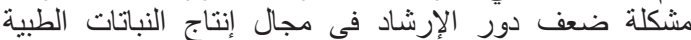

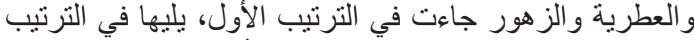

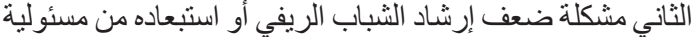

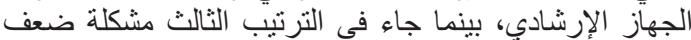

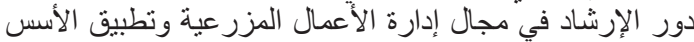

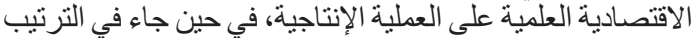

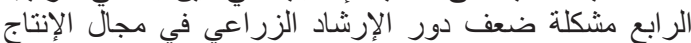

جدول (؛) توزيع المرشدين الزراعيين المبحوثين وفقاً لارجة تواجد المشكلات المتعلقة بمجالات العمل الإرشادي.

\begin{tabular}{|c|c|c|c|c|c|c|c|c|c|c|c|}
\hline \multirow{2}{*}{ الترتيب } & الدرجة & \multicolumn{2}{|c|}{ لا توجد } & \multirow{2}{*}{\multicolumn{2}{|c|}{ صغيرة. }} & \multicolumn{2}{|c|}{ درجهَ التضوطة } & \multirow{2}{*}{ كبيرة - كبرة } & \multirow[b]{2}{*}{ العدد } & \multirow{2}{*}{ المشكلات } & \multirow{2}{*}{ p } \\
\hline & المرجحة & $\%$ & العدد & & & $\%$ & العدد & & & & \\
\hline r & $r, \varepsilon V$ & $7, \wedge$ & 1. & $r, \wedge$ & 1. & 11,9 & rA & $T V, V$ & $1 \ldots$ & في او استبعاده من & 1 \\
\hline 1 & r, Tr & $1 \cdot, 1$ & 10 & $\varepsilon, Y$ & v & $r \wedge, \varepsilon$ & $\leqslant r$ & 07,1 & $\Lambda \varepsilon$ & إغفالّ إرشاد المر أة & r \\
\hline$\varepsilon$ & r, ro & $v, \varepsilon$ & 11 & $r, \varepsilon$ & 。 & ro,A & or & or, s & vq & 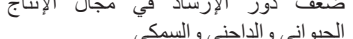 & r \\
\hline 1 & $r, O V$ & $1, \varepsilon$ & r & $\Lambda_{,}$, & ir & $r r$, & $r \varepsilon$ & $T V, V$ & $1 \cdots$ & ورجال إدارة الأعمال إنتاج النباتات & $\varepsilon$ \\
\hline$r$ & $r, \varepsilon r$ & $r, Y$ & $\varepsilon$ & $1 \cdot, \wedge$ & 17 & $r \wedge, \varepsilon$ & $\leqslant r$ & $0 \wedge, 1$ & ᄉт & المزي العملية الإنتاجية الأسس الاقتصادية العلمية & 。 \\
\hline 。 & $r, r \leq$ & $\{, 1$ & 7 & $v, \varepsilon$ & 11 & $r \Lambda, 0$ & ov & $\circ \cdot$, & $v \varepsilon$ & 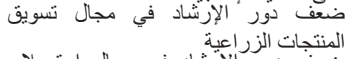 & 7 \\
\hline v & $r, r \leq$ & $\varepsilon, 1$ & 7 & 11,0 & IV & $\varepsilon \cdot, 0$ & 7. & $\varepsilon r, q$ & 70 & في مجال استصلاح & V \\
\hline 11 & $r, \cdot v$ & $1 r, \lambda$ & 19 & $i r, \Lambda$ & 19 & $r q, 1$ & $\leqslant r$ & $\leq 0, r$ & TV & في تنمية المجتمعات & $\wedge$ \\
\hline 9 & r, iv & 7,1 & 9 & $r \leqslant, r$ & rq & $17, r$ & $r \varepsilon$ & or, \{ & va & في اكتشاف وتدريب & 9 \\
\hline$\wedge$ & $r, 11$ & $1 \cdot, 1$ & 10 & $r_{,} \cdot$ & r & $\varepsilon v, r$ & v. & $\varepsilon \cdot, 0$ & 7. & في في مجال البيئة من التلوفة على & 1 . \\
\hline 15 & $1, v r$ & $\mid r, \wedge$ & 19 & $r 7, \leqslant$ & rq & ro,, 1 & or & ro, & rv & قافي وأنتشار الامية بين & 11 \\
\hline ir & $r, r$ & $1 \cdot, \lambda$ & 17 & $1 \leqslant, 9$ & rr & ro,, 1 & or & $r \wedge, 0$ & or & الأسرية في مجال إدارة الأعمال & ir \\
\hline 1. & $r, 1$ & $1 \leqslant, 9$ & rr & 7,1 & 9 & $r r, 1$ & $\leqslant 9$ & $\leq 0,9$ & 71 & الثئئن دالعامة الإرشاد في مجال الإسهام في & 15 \\
\hline
\end{tabular}

جدول (•) توزيع المرشدين الزراعيين المبحوثين وفقاً لارجة تواجد المشكلات المتعلقة بالعاملين الإرشاديين.

\begin{tabular}{|c|c|c|c|c|c|c|c|c|c|c|c|}
\hline \multirow{2}{*}{ الترتيب } & 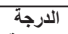 & \multicolumn{2}{|c|}{ لا توجد } & & & \multicolumn{2}{|c|}{ درجه التوطجة } & \multicolumn{2}{|c|}{ كبيرة } & \multirow{2}{*}{ المشكلات } & \multirow{2}{*}{ م } \\
\hline & المرجحة & $\%$ & العدد & & العدد & $\%$ & & $\%$ & العدد & & \\
\hline r & $r, 7$ & $1, \varepsilon$ & r & $1 \cdot, i$ & 17 & $1 \leqslant, \vec{r}$ & I & $\mathrm{v} \tilde{\mathrm{r}}, \mathrm{T}$ & 1.9 & عدم مناسبة المرتبات لطبيعة العمل الإرشادي & 1 \\
\hline$\varepsilon$ & r, & ג', & 1. & ? & - & ri, & $\leqslant 7$ & ז'r, & 94 & ندرة الحيواً & I \\
\hline v & Q & $\hat{s}^{\prime}$, & IT & $1 \cdot 1$ & 10 & $17, r$ & IE & 70,0 & $9 y$ & كأثرة & $\underline{s}$ \\
\hline$\stackrel{\circ}{r}$ & r, & , & $\underline{-}$ & $1 \leqslant 5$ & $\begin{array}{l}1 \\
1 \\
1\end{array}$ & ristra & ra. & 年 & $\begin{array}{l}9 \xi \\
91\end{array}$ & 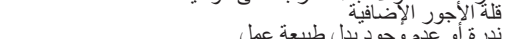 & 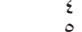 \\
\hline 1 & 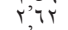 & - & - & ג'י & 1. & r'r & ry & نं', & $1 . \hat{r}$ & & 7 \\
\hline$\wedge$ & $r, \mu \nu$ & $r, \mathrm{r}$ & $\varepsilon$ & $1 \cdot, 1$ & 10 & $r \leqslant, 0$ & 01 & or, $y$ & vA & & $\mathrm{v}$ \\
\hline ro & $1, \wedge \wedge$ & $17, r$ & $r \leqslant$ & ir, & 19 & $r v, \Lambda$ & 07 & rr, & $\leq 9$ & & $\Lambda$ \\
\hline r) & $1,9 v$ & $17, r$ & $r \leq$ & $1 \cdot, 1$ & 10 & $r r, \wedge$ & o. & $r q, 9$ & .99 & 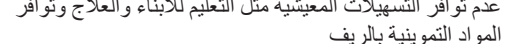 & q \\
\hline rA & 1,17 & $r \cdot, q$ & r & 10,0 & r & $r \cdot, \varepsilon$ & £o & rr, & $\leq 9$ & بالزراع وعقد الاجتماعات & 1 . \\
\hline Tr & $\left\{, \frac{1}{9 y}\right.$ & 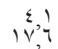 & ry & $\hat{, \hat{r}, \hat{r}}$ & in & $\begin{array}{l}r q, 1 \\
\text { rq, }\end{array}$ & $\left\{\begin{array}{l}r \\
\varepsilon \leq\end{array}\right.$ & $0 \wedge, 1$ & $\uparrow_{7}^{17}$ & 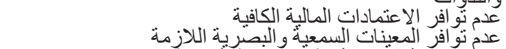 & ir \\
\hline 19 & $r, r$ & $1 \Lambda^{\prime}, r$ & rV & ,', & $q$ & ri,i & $\leqslant$ & $\llbracket \varepsilon_{1}^{\prime}, 7$ & 77 & عدم تو & it \\
\hline 15 & $r, r$ & $0, \xi$ & $\wedge$ & $\uparrow, \wedge$ & 1. & $0 \cdot, \cdot$ & $v \leqslant$ & $r V, A$ & 07 & بحميات دافيه وفي الولت & $1 \leq$ \\
\hline 1. & $r, r \wedge$ & $\wedge, \wedge$ & $1 \pi$ & $\varepsilon$, & 1 & $r v, \wedge$ & 07 & $\varepsilon q, r$ & VT & بغيرها من الوظائف في الجهاز & 10 \\
\hline 11 & $r, Y \varepsilon$ & $v, \varepsilon$ & 11 & 11,0 & iv & $r, 1$ & $\leqslant 7$ & $0 \cdot, \cdot$ & $V \varepsilon$ & رها من الوظائف خارج الجهاز & 17 \\
\hline iv & $r, .0$ & Ir,, & 11 & $1 \leqslant, r$ & r) & rq,, & $\varepsilon \varepsilon$ & $\varepsilon r, q$ & 70 & ضآلة الفرصة أمام الفرد لعمل ما يريد & 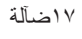 \\
\hline is & $r, r$ & 10,0 & rut & $v, \xi$ & 11 & ro, & or & $\leqslant 1,9$ & $x^{11}$ & ضآلة الفرصة أمام الفرد لتعلم ما بريد & 11 \\
\hline ir & 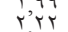 & 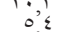 & $i$ & $10^{2}, 0$ & ז' & r., & $\sum_{0}^{2}$ & $\left\{\wedge^{2}\right\}$ & VY & 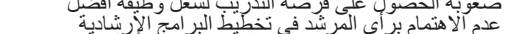 & 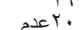 \\
\hline 9 & r, rq & is & 1. & 1,1 & 10 & $r \cdot \xi \xi$ & $\sum_{0}$ & or,y & $\mathrm{vi}$ & عدم تقدير المُنسئولينين الإرش & $\begin{array}{ll}r \\
5\end{array}$ \\
\hline rV & i, & 19,7 & rq & ri,r & 111 & ro' & or & 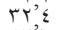 & $\leqslant \wedge$ & عدم تقد & r \\
\hline 1. & או, & $1, \underline{\varepsilon}$ & r & ri, & rr & $r \varepsilon, 0$ & 01 & $\varepsilon r, \tau$ & זו & ضَخَامة & r \\
\hline rq & i'sr & $1 \leqslant ' r$ & (i) & $r \leqslant$ & דז & $r y^{\prime}$. & ؛. & $r \leqslant 0$ & 01 & 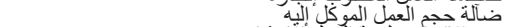 & $r \varepsilon$ \\
\hline$r \varepsilon$ & i, 19 & 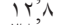 & 19 & r., 9 & r & ५৭,,$Y$ & $\leqslant \varepsilon$ & Ti,0 & $0 \leqslant$ & العمل ألتارشادي & ro \\
\hline rI & i,ro & rAo & ov & $1 r^{\prime}, r$ & 11 & ro,, 1 & or & $1 \varepsilon, r$ & r) & ضعف العلأقات مع الزملاء & ry \\
\hline rT & i’ & $\sum r^{\prime} r$ & $7 \leqslant$ & Ir'r & 11 & ris & $\leqslant v$ & $1 r^{\prime} A$ & 19 & البعد عن الموطن آلصلي و الأهل & rV \\
\hline r. & $i, \leqslant i$ & rq,, & 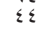 & $1 \lambda^{\prime} 9$ & rA & re, & 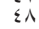 & $1 \Lambda^{\prime}, 9$ & ri & الشعور بالملإ & ri \\
\hline Tr & iar & ir'o & r. & $1 \leqslant 9$ & r & ry'r & 00 & $r \leqslant 0$ & 01 & الالتز اجمبنت & rq \\
\hline 17 & 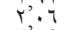 & iro & $r$ r. & $1, \lambda$ & 17 & ris & $\leqslant v$ & $\sum r^{9} q$ & 90 & ندرة فرضم & r. \\
\hline $1 \leqslant$ & iq & $9 \%$ & $1 \leqslant$ & $\varepsilon ' v$ & $\mathrm{v}$ & 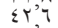 & 许 & rir & $7 \varepsilon$ & عدم تقدير الرو & m \\
\hline rq & 1,77 & $Y T, \varepsilon$ & rq & $17 ' r$ & rs & r'r & r & ro') & or & عدرتوفر الثقة بين الرؤساء والكروُسين & rt \\
\hline
\end{tabular}

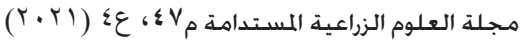


المجلس الأعلى للإرشاد الزراعي كي يكون به نمثنيل حقيقي

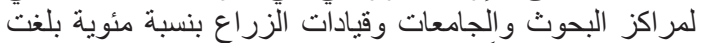

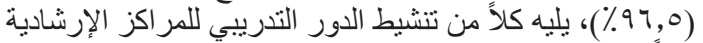

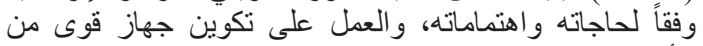

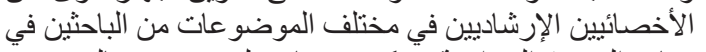

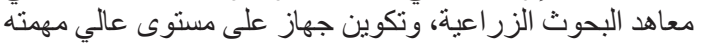

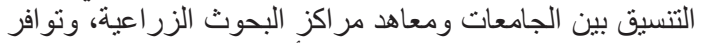

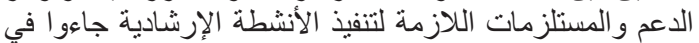

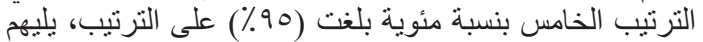

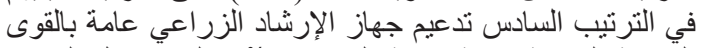

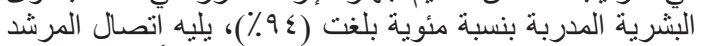

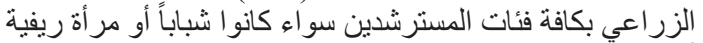

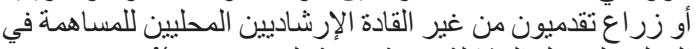

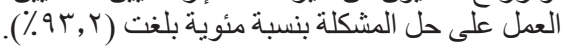

التوصيات

1ـ كثفت الدراسة عن أن ما يقرب من ثناثة أرباع المرشدين

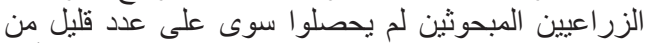

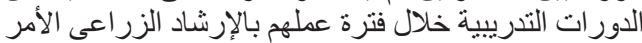

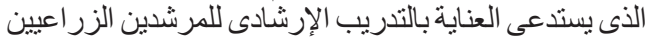

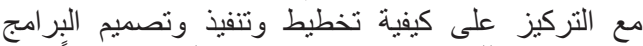
الإرشادية وكذلك كيفية الإستفادة من نتائج التقييم مستقبلاً. r - كثنفت الدراسة عن أن غالبية المرشدين الزر اعيين المبحوثين

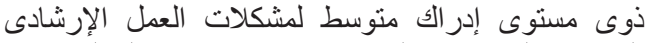

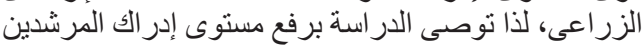

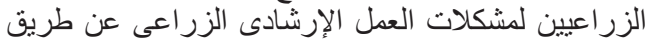

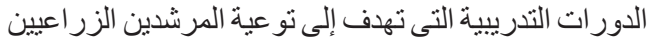

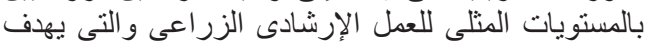
الإرشاد الزر اعى إلى تحقيقها.

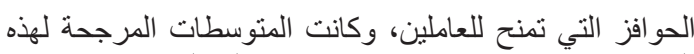

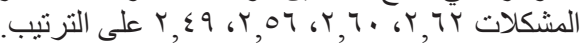

عـ المشكلات المتعلقة بجمهور المسترشدين:

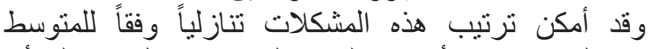

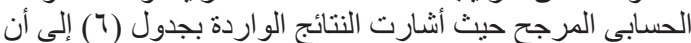

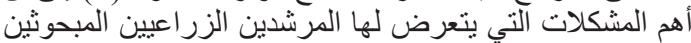

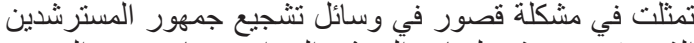

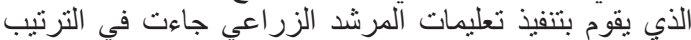

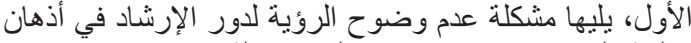

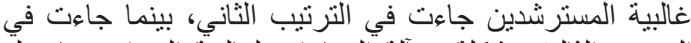

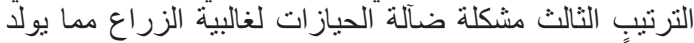

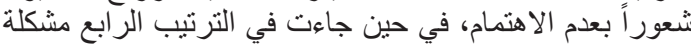

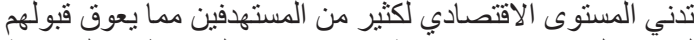

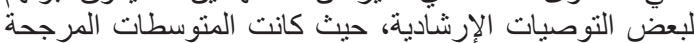

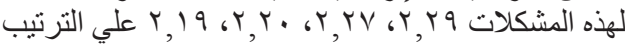
ثالثاً: مقترحات المرشدين الزراعيين المبحوثين للتغلب على تلى

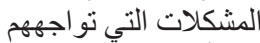

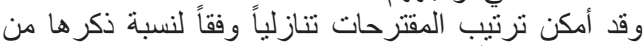

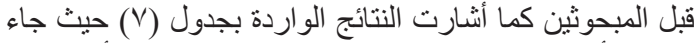

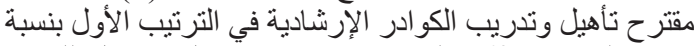

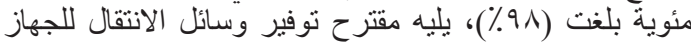

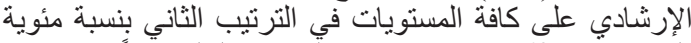

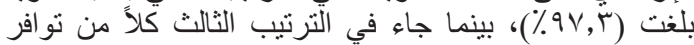

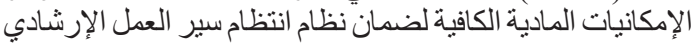

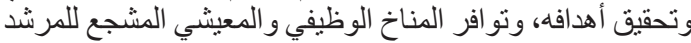

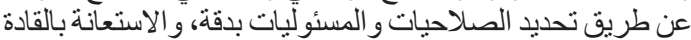

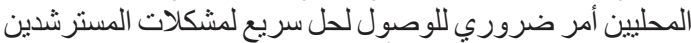

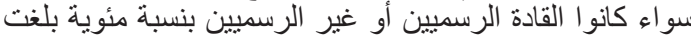

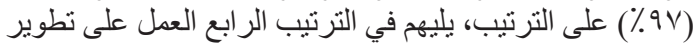

جدول (7) توزيع المرشدين الزراعيين المبحوثين وفقاً لدرجة تواجد المشكلات المتعلقة بجمهور المسترشدين.

\begin{tabular}{|c|c|c|c|c|c|c|c|c|c|c|c|}
\hline \multirow[b]{2}{*}{ الترتيب } & \multirow{2}{*}{ 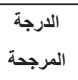 } & \multicolumn{2}{|c|}{ لا توجد } & \multirow{2}{*}{\multicolumn{2}{|c|}{ صغيرة }} & \multirow{2}{*}{\multicolumn{2}{|c|}{ 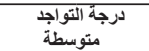 }} & \multirow{2}{*}{\multicolumn{2}{|c|}{ كبيرة }} & \multirow[b]{2}{*}{ المشكلات } & \multirow[b]{2}{*}{ P } \\
\hline & & $\%$ & العدد & & & & & & & & \\
\hline$\varepsilon$ & $r, 19$ & $\wedge, \wedge$ & $1 \pi$ & $1 \cdot, 1$ & 10 & $r r, \wedge$ & 0. & $\varepsilon \vee, r$ & $v$. & تدني المستوى الاقتصادي لكثير من المستهدفين مما يعوق الإنشادية & 1 \\
\hline$r$ & $r, r$. & 11,0 & IV & 9,0 & $1 \varepsilon$ & $r q, \varepsilon$ & rq & or,, & $\vee \wedge$ & 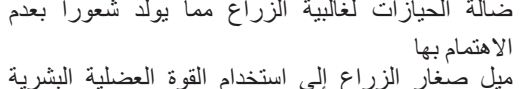 & T \\
\hline ir & $1,7 \leqslant$ & $r\rceil, \varepsilon$ & rq & $1 \leqslant, 9$ & YY & $r V, V$ & §1 & $r, 1$ & $\leqslant 7$ & 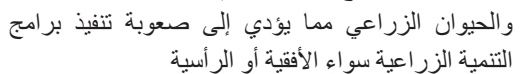 & r \\
\hline$\wedge$ & $1,9 v$ & $1 \leqslant, r$ & rI & $\wedge, 1$ & Ir & $\varepsilon r, q$ & 70 & $r, \wedge$ & 0. & استخدام الزراع طرقاً غير اقتصادية في في إعداد وتسويق & $\varepsilon$ \\
\hline Ir & $1,7 V$ & $1 \leqslant, r$ & rI & $r T$, & $r \varepsilon$ & $\varepsilon \varepsilon, 7$ & 77 & $11, r$ & YV & ارتفاع نسبة الأمية و التخلف الثقافي و الفكري بين الزراع & 0 \\
\hline 11 & 1,19 & ro,, & rᄉ & $\varepsilon, 1$ & 7 & ro, 1 & or & ro, 1 & or & 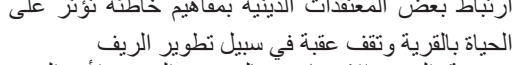 & 7 \\
\hline 1 & $r, \cdot v$ & $\wedge, 1$ & Ir & 10,0 & Yr & $r v, \wedge$ & 07 & $r \wedge, 0$ & or & الاجتماعي يتم ببطء التغير الاجماعي بالمجتمع الريفي لان التغير & V \\
\hline 9 & 1,94 & 'r, & 19 & 17,9 & ro & $r \leqslant, 0$ & 01 & ro, , & or & وقزف الزراعي التيد و العادات حائلا دون & \\
\hline 0 & $r, 1 \varepsilon$ & $1 \cdot, 1$ & 10 & $1 T, 0$ & $r \cdot$ & rq, 1 & $\leqslant r$ & $\varepsilon \vee, r$ & v. & شظكرة الريفي إلى الهيئات الحكومية وشبه الحكومية نظرة & 9 \\
\hline $1 \cdot$ & $1, \wedge \varepsilon$ & $r T$, & $r \leqslant$ & $1 \leqslant, r$ & r) & $11, r$ & TV & $\varepsilon \varepsilon, 7$ & 77 & عدم قبول الزر اع للجديد ومعارضتهم للتجديد & 1. \\
\hline V & $1,9 \vee$ & 17,9 & ro & \urcorner,$\wedge$ & 1. & $r \Lambda, 0$ & or & $r v, \wedge$ & 07 & & 11 \\
\hline 1 & $r, r q$ & $\wedge, 1$ & Ir & 9,0 & $1 \leqslant$ & $r v, V$ & $\leqslant 1$ & $0 \leqslant, V$ & 11 & قتنفيذ تعليمات في وسائل تشجيع جمهور الزمسترشدين الذي يقوم & Ir \\
\hline r & $r, Y V$ & $0, \varepsilon$ & $\wedge$ & $\wedge, \wedge$ & 14 & $r q, r$ & 01 & $\leq 7,7$ & 79 & المسترش وضوح الرؤية لدور الإرشاد في أذهان غالبية & 14 \\
\hline
\end{tabular}

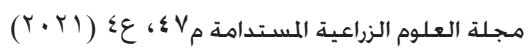


جدول (V) مقترحات المرشدين الزراعيين للتظلب على مشكلات العمل الإرشادي.

\begin{tabular}{|c|c|c|c|c|}
\hline الترتيب & $\%$ & العدد & المقترحات & s \\
\hline r & $9 \vee$, & $1 \leqslant r$ & تو افر الإمكانيات المادية الكافية لضمان نظام انتظام سير العمل الإرشادي وتحقيق أهدافه & 1 \\
\hline$\wedge$ & $9 r^{\prime}$, & 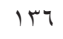 & اعتماد ميز انية ثابتة تكفي لحجم المهام الإرشادية المطلوب أدائها & r \\
\hline r & $9 \vee, r$ & $1 \leq \varepsilon$ & توفير وسائل الانتقال للجهاز الإرشادي على كافة المستويات & r \\
\hline 9 & $91, r$ & iro & توفير حو افز مادية ثابتة لمن يؤدي عملَه من المرشدين فقط & $\varepsilon$ \\
\hline$\circ$ & 90, & $1 \leq$. & 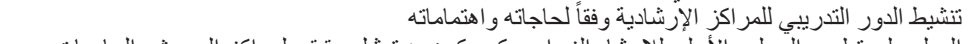 & 0 \\
\hline$\varepsilon$ & 97,0 & IYA & 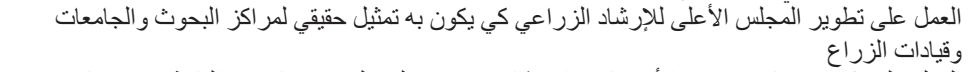 & 7 \\
\hline 0 & 90 , & $1 \leq$ & البحوث على تكوين جهاز قوى من الأخصائيين الإرشاديين في مختلف الموضو عات من الباحثين في معاهد & V \\
\hline 1 & $9 \wedge$, & $1 \leq 0$ & تأهيل وتدريب الكو ادر الإرشادية & $\Lambda$ \\
\hline r & $9 \vee$, & $1 \leqslant r$ & تو افر المناخ الوظيفي و المعيشي المشجع للمرشد عن طريق تحديد الصلاحيات و المسئوليات بدقة & 9 \\
\hline 11 & $19, Y$ & Tr & تخصيص بدل إرشادي ميداني & 1 . \\
\hline 1 & $9 \leqslant$, & 149 & تدعيم جهاز الإرشاد الَّر اعي عامة بالقوى البشرية المدربة & 11 \\
\hline ○ & $90^{\prime}$, & $1 \leq$. & تكوين جهاز على مستوى عالّي مهته التنسيق بين الجامعات ومعاهد مر اكز البحوث الزر اعية & ir \\
\hline ir & $\wedge \wedge$, & $1 \mathrm{~s}$. & التو عية المستمرة بمبادئ الإرشَّاد الزر اعي السليمة & 14 \\
\hline 1. & $9 \cdot, 0$ & $1 T \leq$ & أن تتضمن بر امج التدريب للعاملين الإرشآديين موضو عات تتعلق بمفهوم الإرشاد الزر اعي وفلسفته & $1 \leq$ \\
\hline iv & $V \tau, \xi$ & 111 & لا مركزية تخطيط وتنفيذ البر امج و الأنشطة الزراعية & 10 \\
\hline 0 & 90, & $1 \leq$. & تو افر الدعم و المستلزمات اللازمة لتتفيذ الأنشطة الإرشادية & 17 \\
\hline$\Lambda$ & $94, \cdot$ & 147 & ربط أداء العمل الإرشّادي بالحافز & IV \\
\hline $1 \varepsilon$ & $\Lambda V^{\prime}, \mathrm{r}$ & 149 & جعل عمل المرشد في مكّان إقامته & 11 \\
\hline 10 & $\Lambda \varepsilon$, & 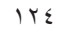 & توفر الأدوات المكتيةًة & 19 \\
\hline ir & $\Lambda \Lambda, 0$ & 14 & تقليل مساحة الأر اضي الزر اعية المطلوب من المرشد تغطيتها & r. \\
\hline 17 & $\mathrm{VV}$, & $11 \leq$ & تزويد الرقابة و الإشر آف على المرشدين الزر اعيين في المر اكز الإرشادية & Y) \\
\hline r & १४, & $1 \leq r$ & أو غير الرسميينة بالقادة المحليين أمر ضروري للوصول لحل سريع لمشكلات المسترشدين سو اء كانو ا القادة الرسميين & YY \\
\hline $1 \pi$ & $\wedge \wedge$, & . & لمواجهة المشكلة المشر المي ببعض المنظمات الموجودة في نطاق المشكلة طلباً للمعونة أو المشورة أو لتعبئة الجهود & $r r$ \\
\hline V & $q r, r$ & $1 \mathrm{H}$ & 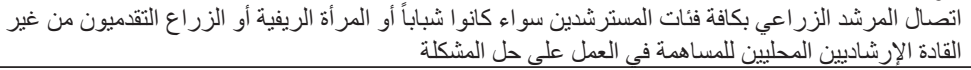 & $Y \varepsilon$ \\
\hline
\end{tabular}

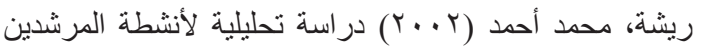

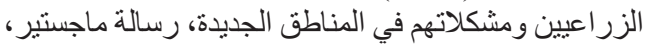

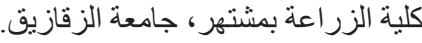

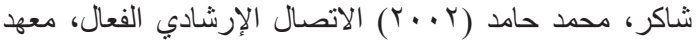

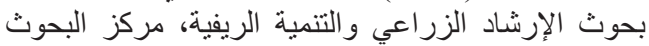

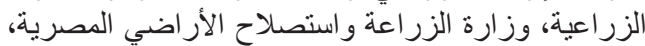

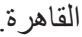

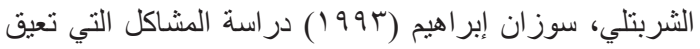

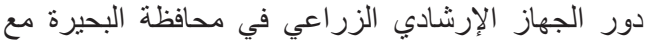

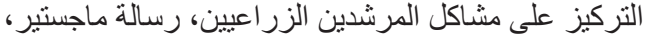
كلية الزر اعة، جامعة الاسكندرية.

شلبي ، رجاء حامد، وماري بشرى ميخائيل، و عبدالغني محمد

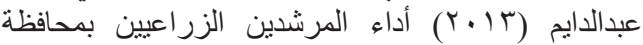

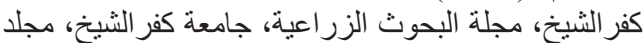

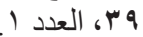

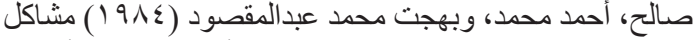

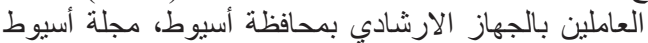

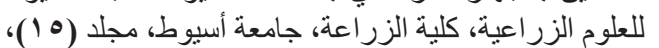

العدد (l) (l)

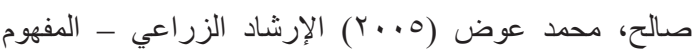

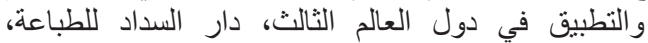

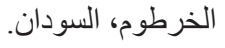

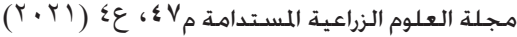

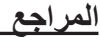

أو لاً: مر اجع باللغة العربية

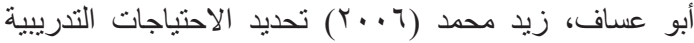

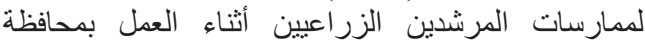
القليوبية، رسالة ماجستير، كلية الزر اعة، جامعة عين شمس.

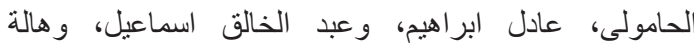

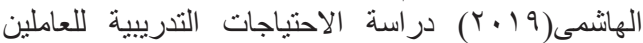
الارشاديين في مجال التغير ات المناخية و اثر ها على الانتاج

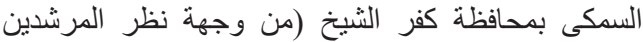

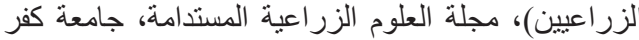

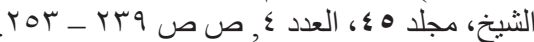

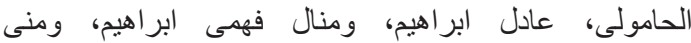

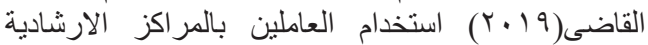

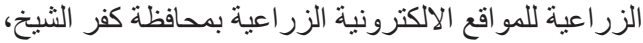

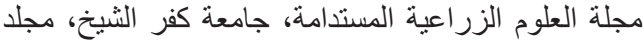

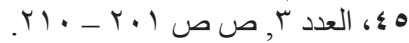

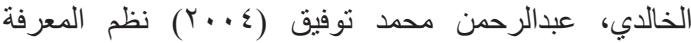

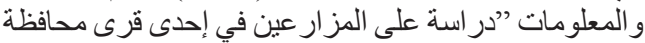
الجيزة“، رسالة دكتور اه، كلية الزر اعة، جامعة جامعة القاهرة.

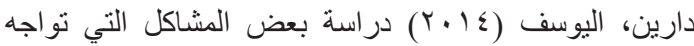

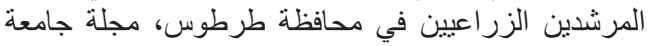

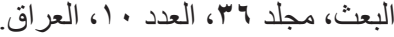




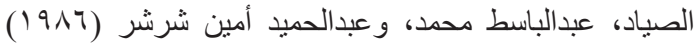

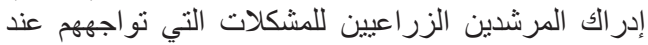

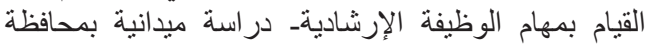

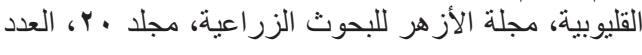

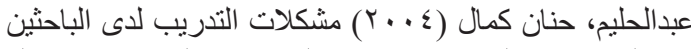

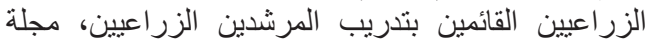
الجمعية العلمية للإرشاد الزر اعي، المجلد الثامن.

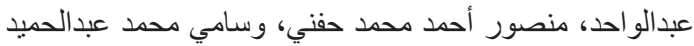

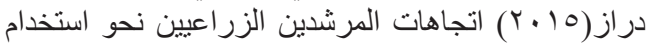

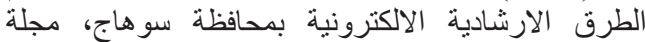

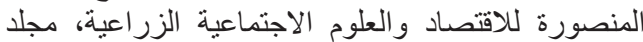

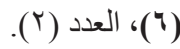

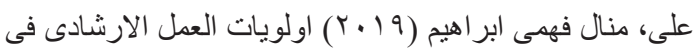

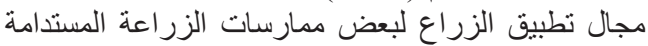

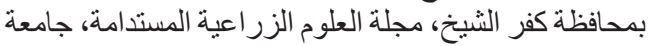

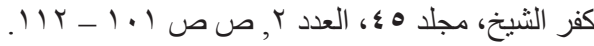

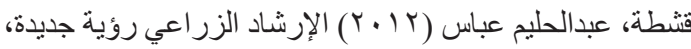
دار الندى للطباعة، القاهرة.

قنديل، ممدوح شعبان (1999) تقييم الآداء الوظيفي للمرشدين

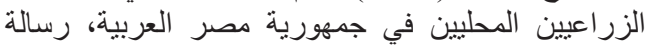

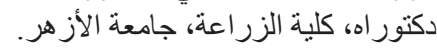

مجد، زينب حسن (1990) بعض المتغير ات المؤثرة على أداء

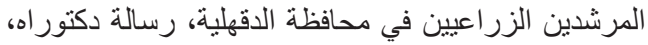
كلية الزر اعة، جامعة القاهرة فئرة

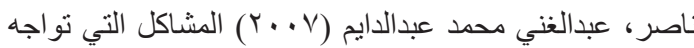

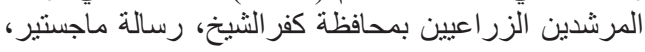
كلية الزر اعة، جامعة كفر الشيخ.

هيكل، سحر عبدالخالق، و عبدالمنعم محمد كوكب، و وعماد الحسيني

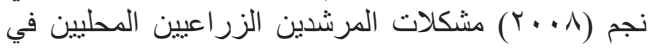

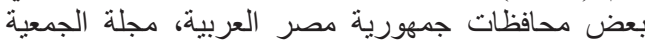
العلمية للإرشاد الزر اعي، مجلد (r I ) العدد (r I ).

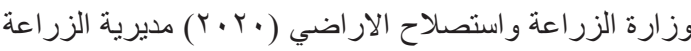
بكفر الثيخ، بيانات رسمية غير منشورة النئ.

و هبه، أحمد جمال الدين، وسعد الدين محمد عبدالعال (991 (19 )

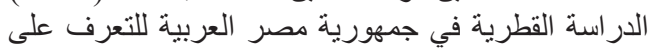
عناصر الإرشاد التسويقي في مجال تسويق المئية المحاصيل

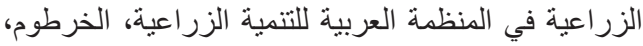

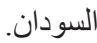
ثانياً: المر اجع الأجنبية

Adams ME (1988) Agricultural Extension in Developing countries. Logman Group. England. 


\title{
Problems Facing Agricultural Extension Workers and their Suggestions to Overcome them in Kafr El-Sheikh Governorate
}

\author{
Ahmed M. Abdullah', Ahmed M. Amer and Salah E. Amer ${ }^{2}$ \\ ${ }^{1}$ Agricultural Econmic Dept. Faculty of Agriculture, Kafrelsheikh University, \\ ${ }^{2}$ Institute of Agric. Extension and Rural Development, Agric. Researches center, Egypt
}

$\mathbf{T}$

HIS RESEARCH mainly aimed to identify the problems facing agricultural extension workers and their proposals to overcome them in Kafr El-Sheikh Governorate. A regular random sample of $20 \%$ of the total extension specialists working in Kafr El-Sheikh Governorate was selected, and it consisted of (30) agricultural extension specialists, and (118) As an agricultural guide, several statistical methods were used, represented by: frequencies, percentage, arithmetic mean, standard deviation, and weighted arithmetic mean, using the SPSS statistical program to analyze the research data, and the most important results were: They are the problems related to the management of the extension work, which are related to the extension work areas, which are related to the extension workers, and which are related to the counseling public. These problems have been arranged according to their relative importance from the respondents' point of view. Sub-problems include the weak role of extension in the field of medicinal and aromatic plants and flowers production, followed by problems related to Iraqi workers Shadyen and its main sub-problems are the low job income compared to other jobs, then the problems related to the management of extension work. Cooperators with the extension in the implementation of extension activities, and the most important proposals of the counselors surveyed in overcoming these problems came in: Rehabilitation and training of agricultural extension cadres, providing transportation means for the extension body, the availability of sufficient financial capabilities to ensure the regularity of the extension work and achieving its objectives, and creating the appropriate job environment for the work Agricultural guide.

Keywords: Agricultural extension, problem, agricultural extension. 